\title{
The Decision-Making Approach Based on the Combination of Entropy and Rov Methods for the Apple Selection Problem
}

\author{
Ayşegül Tuş Işık \\ Department of Business Administration, Pamukkale University, \\ Esra Aytaç Adalı \\ Department of Business Administration, Pamukkale University, Denizli, Turkey,
}

\begin{abstract}
Apple juice concentrate is the second consumed fruit juice all around the world, behind the orange juice concentrate. The characteristics of the apple juice concentrate namely the acidity level and the sweetness of the processed product vary depending on the variety of the apple. So the selection of the most appropriate apple among the alternatives in the fresh market is not easy task for food companies. This selection may be handled as Multi Criteria Decision Making (MCDM) problem. This paper presents the new decision making approach based on two MCDM methods, Entropy and ROV (Range of Value), for the apple selection problem of a food company that produces apple juice concentrate. Entropy method determines the weights of the criteria whereas ROV method ranks the alternatives. The invention of this paper is Entropy and ROV are combined firstly in the literature.
\end{abstract}

Keywords: MCDM, Entropy, ROV, apple selection

\section{Introduction}

Apples are more widely grown than any other fruits; hundreds of apple cultivars are grown all around the world (Root, 1996). While some apple cultivars are grown exclusively for use in processing, some of them are used in processed products. Perfectly good fruit from the commercial fresh market cultivars are used for processing. In other words only sound, ripe fruit should be used for further processing because decay, damage, maturity, firmness, colour, soluble solids, acids and tannins of the fruit affect the quality of the product. So selecting apple for the food companies is difficult because of these various criteria that influence the companies to make this decision (Bates et al., 2001). In the literature, Multi Criteria Decision Making (MCDM) methods have not been yet applied to the apple selection problem of the food companies. In this paper, Entropy and ROV (Range of Value) methods are combined for selecting the most appropriate apple for the food company to make apple juice concentrate. The weights of the criteria are determined with Entropy method and the ranking of the alternatives are determined with ROV method.

The rest of this paper is organized as follow. In Section 2, the new combined decision making approach based on Entropy and ROV methods is introduced. In Section 3, this approach is applied to the apple selection problem of a food company. In Section 4 the results of the application are presented and recommendations for future studies are discussed.

\section{The New Combined Decision Making Approach}

The new combined decision making approach starts with identification of the problem and the selection of decision makers. Then the criteria and alternatives associated with the problem are determined and necessary data are gathered. Entropy and ROV methods are applied for determining the weights of the criteria and determining the ranking of the alternatives respectively. The procedure of the selection problem is shown in Figure 1 as a flowchart. 


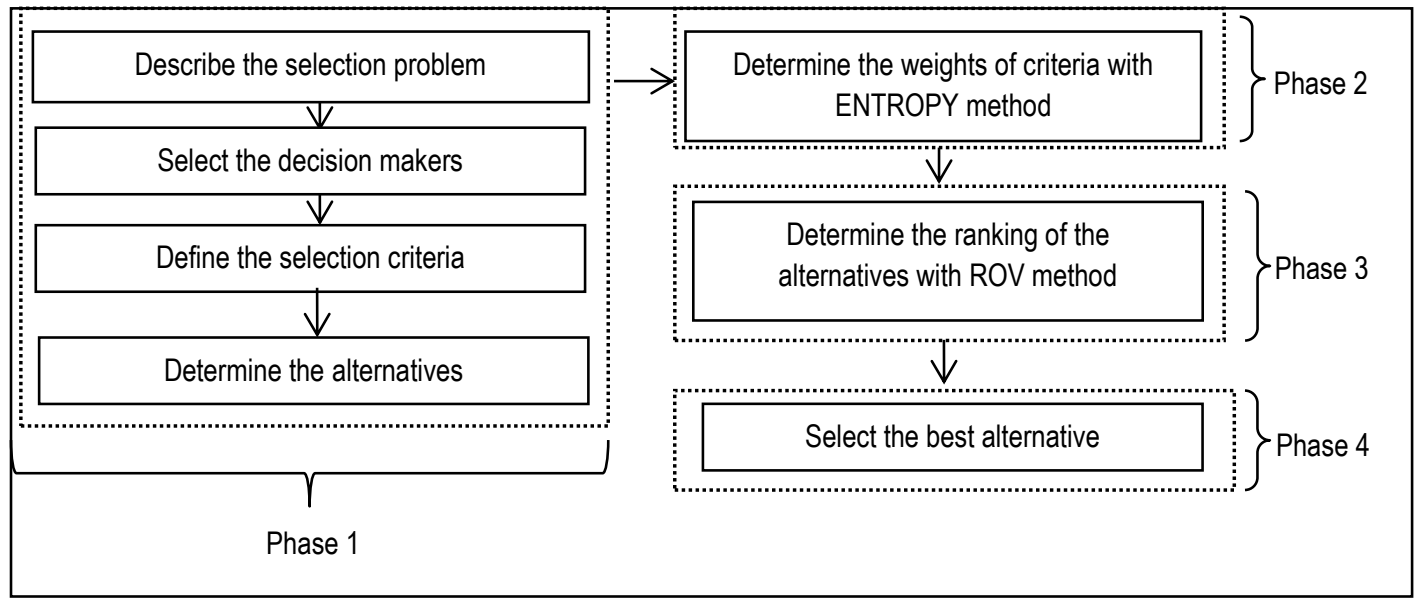

Figure 1. The procedure of the proposed decision making approach

\subsection{Entropy Method}

Entropy method is a measure of uncertainty in information formulated in terms of probability theory. It was initially derived from thermodynamics by Rudolph Clausius (1865) and used to describe the irreversible phenomenon of a motion or a process (Mon et al., 1994). The concept of information entropy was first introduced by Claude E. Shannon (1948). Nowadays, it has been widely used in engineering, economy, finance etc. Information entropy is the measurement of the disorder degree of a system. It can measure the amount of useful information with the data provided. When the difference of the value among the evaluating objects on the same indicator is high, while the entropy is small, it illustrates that this indicator provides more useful information, and the weight of this indicator should be set correspondingly high. On the other hand, if the difference is smaller and the entropy is higher, the relative weight would be smaller. Hence, the entropy theory is an objective way for weight determination (Zou et al., 2006).

In the literature Entropy method and its extensions have been employed to solve MCDM problems. Mon et al. (1994) used fuzzy AHP (Analytic Hierarchy Process) based on entropy weight for evaluating weapon system. Deng et al. (2000) suggested that the modified TOPSIS (Technique for Order Preference by Similarity to Ideal Solution) approach with objective weights obtained from the Entropy method is suitable for the inter-company comparison problem examined. Zou et al. (2006) determined the weight of evaluating in fuzzy synthetic evaluation for water quality assessment indicators with Entropy method. Li et al. (2011) applied entropy weight and TOPSIS method in safety evaluation of coal mines. Shemshadi et al. (2011) applied a fuzzy VIKOR (Vise Kriterijumska Optimizacija I Kompromisno Resenje) method for supplier selection based on entropy measure for objective weighting. Zhengyuan et al. (2011) used entropy weight fuzzy comprehensive model for the evaluation research of regional power grid companies' operation capacity. Zhang et al. (2011) combined IEW (Information Entropy Weight) with TOPSIS method for the evaluation of tourism destination competitiveness in the Yangtze River Delta of China. Wu et al. (2011) proposed an approach based on information entropy theory instead of calculating the average cross efficiency scores. Safari et al. (2012) applied PROMETHEE (Preference Ranking Organization METHod for Enrichment of Evaluations) method based on entropy weight for supplier selection. Pani et al. (2012) proposed a heuristic method AET as a combination of AHP, Entropy and TOPSIS to select the best supplier. Li et al. (2014) proposed a customer satisfaction evaluation method for customized product development using entropy weight and AHP. Islamoglu et al. (2015) measured the financial performance of real estate investment trusts by using entropy based TOPSIS. Liu et al. (2015) presented a novel approach for failure mode and effects analysis based on combination weighting and fuzzy VIKOR method. Combination of fuzzy AHP and Entropy method was applied for risk factor weighting. Fuzzy VIKOR method was used to determine the risk priorities of failure modes. Xu et al. (2016) proposed the SWOT (Strengths, Weaknesses, Opportunities, Threats) -TOPSIS integrated model combined with AHP and Entropy method for the development strategy of China's rural drinking water. 
The application steps of Entropy method are presented in the following (Li et al., 2011). Firstly it is assumed that there is a set of $m$ feasible alternatives, $A_{i}(i=1,2, \ldots, m)$ and $n$ evaluation criteria $C_{j}(j=1,2, \ldots, n)$ in the problem.

Step 1: The decision matrix $X$ which shows the performance of different alternatives with respect to various criteria is formed.

$$
X=\left[x_{i j}\right]_{m \times n}=\left[\begin{array}{cccc}
x_{11} & x_{12} & \cdots & x_{1 n} \\
x_{21} & x_{22} & \cdots & x_{2 n} \\
\vdots & \vdots & \ddots & \vdots \\
x_{m 1} & x_{m 2} & \cdots & x_{m n}
\end{array}\right] \quad(i=1,2 \ldots, m ; j=1,2, \ldots, n)
$$

$x_{i j}$ presents the performance value of $i$ th alternative on $j$ th criterion.

Step 2: The decision matrix is normalized. Beneficial (maximization) and non-beneficial (minimization) criteria are normalized by Eq. (2) and Eq. (3) respectively. To have the performance measures comparable and dimensionless, all the entries of the decision matrix are linear normalized using the following two equations:

$$
\begin{array}{ll}
r_{i j}=\frac{x_{i j}-\min \left(x_{i j}\right)}{\max \left(x_{i j}\right)-\min \left(x_{i j}\right)} & \mathrm{i}=1,2, \ldots, \mathrm{m} \text { and } \mathrm{j}=1,2, \ldots, \mathrm{n} \\
r_{i j}=\frac{\max \left(x_{i j}\right)-x_{i j}}{\max \left(x_{i j}\right)-\min \left(x_{i j}\right)} & \mathrm{i}=1,2, \ldots, \mathrm{m} \text { and } \mathrm{j}=1,2, \ldots, \mathrm{n}
\end{array}
$$

Step 3: Entropy values $\left(e_{j}\right)$ are determined for each criterion.

$$
e_{j}=-\frac{\sum_{i=1}^{m} f_{i j} \ln f_{i j}}{\ln m} \quad i=1,2, \ldots, m \text { and } j=1,2, \ldots, n
$$

where $f_{i j}=\frac{r_{i j}}{\sum_{i=1}^{m} r_{i j}}$ and $0<e_{j}<1$.

If $f_{i j}$ are all the same, then the entropy values of each criterion is the maximum $\left(e_{j}=1\right)$. If $f_{i j}$ is 0 , then $f_{i j} \ln f_{i j}$ is 0 (Wu et al., 2011).

Step 4: Entropy weights $\left(w_{j}\right)$ are calculated.

$$
w_{j}=\frac{1-e_{j}}{n-\sum_{i=1}^{m} e_{j}} \text { where } \sum_{j=1}^{n} w_{j}=1
$$

$\left(1-e_{j}\right)$ represents the inherent contrast intensity of each criterion. In other words it is the degree of divergence of the intrinsic information of each criterion. If $\left(1-e_{j}\right)$ is normalized, then the final weights of each criterion can be obtained. The entropy weight is a parameter that describes the importance of the criterion. The smaller the value of the entropy, the larger the entropy-based weight, then the specific criterion provides more information and this criterion becomes more important than the other criteria in the decision making process (Wu et al., 2011).

\subsection{ROV Method}

The ROV (Range of Values) method was proposed by Yakowitz et al. (1993). It requires only ordinal specification of criteria importance from a decision maker. Thus, in situations where decision makers are facing problems in supplying quantitative weights, the application of the ROV method can be particularly useful. The ROV method calculates the best and worst utility for each alternative. This is achieved by maximizing and minimizing a utility function (Hajkowicz and Higgin, 2008). This 
method computes all the possible combinations of cardinal values for indicator weights which are consistent with the decision maker's ordinal weighting and computes the range of possible values for the final score.

In the literature ROV method has very limited applications. It has been applied to problems of watershed management by Yakowitz and Lane (1997) and Yakowitz and Hipel (1997) (Hajkowicz and Higgin, 2008). Salazar et al. (1998) compared three MCDM methods; ELECTRE (Elimination Et Choix Traduisant la Realité) II, Q-analysis and ROV for a water management problem in an irrigation district in Mexico. Hajkowicz and Higgins (2008) applied SAW (Simple Additive Weighting), ROV, PROMETHEE II, Evamix (Evaluation of Mixed Data) and compromise programming methods to six water management decision problems from the literature and suggested that more emphasis has to be given on the initial structuring of the decision problem, involving choosing the relevant criteria and alternative decisions. Athawale and Chakraborty (2011) considered ten MCDM methods including ROV method and their relative performance for the robot selection problem. Jha et al. (2013) used ROV method for supplier selection. Madić et al. (2015) proposed a ROV-based Taguchi methodology is for multi-objective optimization of laser cutting. Madić et al. (2016) used ROV method for solving the cutting fluid selection problems.

In ROV method it is also assumed that there is a set of $m$ feasible alternatives, $A_{i}(i=1,2, \ldots, m)$ and $n$ criteria $C_{j}(j=1,2, \ldots, n)$. The application steps of ROV method are presented in the following (Madić and Radovanović, 2015; Hajkowicz and Higgin, 2008):

Step 1: The decision matrix $X$ which shows the performances of different alternatives with respect to various criteria is formed. The decision matrix is presented in Eq. (1).

Step 2: The decision matrix is normalized by using Eq. (2) and Eq. (3) for beneficial and non-beneficial criteria respectively.

Step 3: The best and worst utility for each alternative are calculated. This is achieved by maximizing and minimizing a utility function. For a linear additive model, the best utility $\left(\mathrm{u}_{i}^{+}\right)$and the worst utility $\left(\mathrm{u}_{i}{ }^{-}\right)$of ith alternative are obtained using the following equations:

Maximize: $u_{i}^{+}=\sum_{j=1}^{n} r_{i j} w_{j}$

Minimize: $u_{i}^{-}=\sum_{j=1}^{n} r_{i j} w_{j}$

where $w_{j}(j=1, \ldots, n)$ are criteria weights which satisfy $\sum_{j=1}^{n} w_{j}=1$ and $w_{j} \geq_{0}$

If $u_{i}^{-}>u_{i^{\prime}}^{+}$, then alternative i outperforms alternative $i^{\prime}$ regardless of the actual quantitative weights. If it is not possible to differentiate the alternatives on this basis then a scoring can be attained from the midpoint, which can be calculated as:

$u_{i}=\frac{u_{i}^{-}+u_{i}^{+}}{2}$

In this final step the complete ranking of the alternatives is obtained on the basis of ui values. Thus, the best alternative has the highest ui value and the worst alternative has the lowest ui value.

\section{Application}

In this section, in order to demonstrate the applicability of the Entropy and ROV methods, apple selection problem of a food company is considered. This company operates in Denizli and processes apples for apple juice concentrate. In this company the staffs from the quality control laboratory is responsible from finding apples from the regions around and analyze them if they suitable or not. Firstly they consider five criteria affecting their selection decision as acidity $\left(\mathrm{C}_{1}, \mathrm{gr} / \mathrm{t}\right)$, brix $\left(\mathrm{C}_{2}\right)$, decay $\left(\mathrm{C}_{3}, \%\right)$, foreign material $\left(\mathrm{C}_{4}, \%\right)$ and cost $\left(\mathrm{C}_{5}, \mathrm{TRY}\right)$. Among these criteria $\mathrm{C}_{2}$ is the beneficial criterion where higher values are desirable; $C_{1}, C_{3}, C_{4}$ and $C_{5}$ are non-beneficial criteria where smaller value is always preferred. 
Considering these criteria the staffs from the quality control laboratory of the food company determines 4 different apples growing in different regions $\left(A_{1}, A_{2}, A_{3}, A_{4}\right)$ for making apple juice concentrate. After making necessary analysis they form the decision matrix of the apple selection problem. Table 1 shows the decision matrix.

Table 1. Decision matrix

\begin{tabular}{llllll}
\hline & $\mathbf{C}_{1}$ & $\mathbf{C}_{2}$ & $\mathbf{C}_{3}$ & $\mathbf{C}_{4}$ & $\mathbf{C}_{5}$ \\
\hline $\mathbf{A}_{1}$ & 3,6 & 20 & 2 & 0,3 & 0,16 \\
$\mathbf{A}_{2}$ & 3,4 & 16 & 2 & 0,1 & 0,19 \\
$\mathbf{A}_{3}$ & 3,2 & 20 & 5 & 0,2 & 0,14 \\
$\mathbf{A}_{4}$ & 3 & 17 & 3 & 0,5 & 0,14
\end{tabular}

\subsection{Application of Entropy Method}

In this section the weights of each criterion are determined by the Entropy method. Firstly, the decision matrix is normalized by using Eq. (2) and Eq. (3) for beneficial and non-beneficial criteria respectively and shown in Table 2. Then the entropy values are determined for each criterion and entropy weights are calculated by using Eq. (4) and Eq. (5).

Table 2. Normalized decision matrix

\begin{tabular}{llllll}
\hline & $\mathbf{C}_{1}$ & $\mathbf{C}_{2}$ & $\mathbf{C}_{3}$ & $\mathbf{C}_{4}$ & $\mathbf{C}_{5}$ \\
\hline $\mathbf{A}_{1}$ & 0,0000 & 1,0000 & 1,0000 & 0,5000 & 0,6000 \\
$\mathbf{A}_{2}$ & 0,3333 & 0,0000 & 1,0000 & 1,0000 & 0,0000 \\
$\mathbf{A}_{3}$ & 0,6667 & 1,0000 & 0,0000 & 0,7500 & 1,0000 \\
$\mathbf{A}_{4}$ & 1,0000 & 0,2500 & 0,6667 & 0,0000 & 1,0000 \\
\hline
\end{tabular}

Table 3. Entropy values and entropy weights

\begin{tabular}{llllll}
\hline & $\mathrm{C}_{1}$ & $\mathrm{C}_{2}$ & $\mathrm{C}_{3}$ & $\mathrm{C}_{4}$ & $\mathrm{C}_{5}$ \\
\hline Entropy values $\left(\mathrm{e}_{\mathrm{j}}\right)$ & 0,7296 & 0,6961 & 0,7806 & 0,7652 & 0,7743 \\
Entropy weights $\left(\mathrm{w}_{\mathrm{j}}\right)$ & 0,2156 & 0,2423 & 0,1749 & 0,1872 & 0,1800
\end{tabular}

According to the Table 3 , the $\mathrm{C}_{2}$ (brix) is the most important criterion with the highest entropy weight. $\mathrm{C}_{1}$ (acidity), $\mathrm{C}_{4}$ (foreign material), $C_{5}$ (cost) and $C_{3}$ (decay) follow this criterion respectively.

\subsection{Application of ROV Method}

ROV method is used for ranking the alternatives. Firstly, the normalized decision matrix that is obtained by using Eq. (2) and Eq. (3) is used as shown in Table 2. Then the best and the worst utility functions for each alternative are calculated by using Eq. (6) and Eq. (7). The criteria weights derived from Entropy method is used while making these calculations. Finally, the $u_{i}$ values of all alternatives with respect to the considered criteria are estimated by using Eq. (8). Table 4 exhibits results of the ROV method upon which complete ranking of the alternatives is obtained.

Table 4. Ranking of alternatives

\begin{tabular}{lllll}
\hline Alternatives & $u_{i}^{+}$ & $u_{i}^{-}$ & $u_{i}$ & Rank \\
\hline $\mathrm{A}_{1}$ & 0,2156 & 0,4528 & 0,3342 & 2 \\
$\mathrm{~A}_{2}$ & 0,0000 & 0,5031 & 0,2516 & 4 \\
$\mathrm{~A}_{3}$ & 0,2156 & 0,5211 & 0,3684 & 1
\end{tabular}



$\mathrm{A}_{4}$
0,0539
0,5750
0,3144
3

According to Table 4, the ranking of the alternatives is $A_{3}>A_{1}>A_{4}>A_{2}$. For this problem $A_{3}$ is the best alternative with the highest utility value and $A_{2}$ is the worst alternative with the lowest utility value.

\section{Conclusion}

In this paper the apple selection problem of the food company for the apple juice concentrate has been solved with the Entropy and ROV methods. After making necessary operations of these methods the best apple from different regions is determined. The Entropy method is used to determine the criteria weights and the ROV method is used to obtain complete ranking of alternatives. The Entropy and ROV methods provide some advantages to the decision makers. Entropy method measures the relative contrast intensities of the criteria to represent the average intrinsic information transmitted to the decision maker (Shemshadi et al., 2011). This method determines the weights of criteria objectively without considering the decision makers' preferences. So it can be particularly applicable for situations where reliable subjective weights cannot be obtained (Deng et al., 2000). According to the idea of information entropy, the number or quality of information acquired from decision making setting is one of the determinants of accuracy and reliability of decision making problem. Entropy is therefore a very good scale when it is applied to different cases of assessment or evaluation in different decision making process, and similarly, entropy can also be used to measure the quantity of useful information provided by data itself (Wu et al., 2011). On the other hand the ROV method calculates the best and worst utility for each alternative (Hajkowicz and Higgin, 2008). This method computes all the possible combinations of cardinal values for indicator weights which are consistent with the decision maker's ordinal weighting and computes the range of possible values for the final score.

Both methods are based on evaluation matrix and they can simultaneously consider any number of criteria and alternatives. So complex decision problems can be organized and solved in a consistent manner. They handle the beneficial and nonbeneficial criteria in the problem separately. They contain simple computational procedure. So they are easy to apply to the many real life selection problems. These methods are suitable for the analysis of alternatives' performance with respect to various conflicting criteria both qualitative and quantitative. The combination of these two methods enables taking advantages of their strengths.

This paper shows that the Entropy and ROV methods are performed efficiently for the apple selection problem. In future studies, proposed combined approach may also be applied to other selection problems of the company. The number of the evaluation criteria and the alternatives may be changed according to the needs of the company. The weights of the criteria may be derived from different weighting methods. The ranking of the alternatives may be performed with other MCDM methods and the obtained results may be compared.

\section{Acknowledgments}

This paper was financially supported by the Scientific Research Projects Coordination Unit of Pamukkale University.

\section{References}

[1] Athawale, V. M., \& Chakraborty, S. (2011). A comparative study on the ranking performance of some multi-criteria decision-making methods for industrial robot selection. International journal of industrial engineering computations, 2(4), 831-850.

[2] Bates R. P., Morris J. R. \& Crandall P.G. (2001). Principles and practices of small-and medium-scale fruit juice processing, Food \& Agriculture Org. Agricultural Services Bulletin, No. 146, Rome.

[3] Clausius, R. (1865). Ueber verschiedene für die Anwendung bequeme formen der Hauptgleichungen der mechanischen Wärmetheorie. Ann. Phys. Chem., 125, 53-400.

[4] Deng, H., Yeh, C. H., \& Willis, R. J. (2000). Inter-company comparison using modified TOPSIS with objective weights. Computers and Operations Research, 27, 963-973.

[5] Hajkowicz, S., \& Higgins, A. (2008). A comparison of multiple criteria analysis techniques for water resource management. European journal of operational research, 184(1), 255-265.

[6] Islamoglu, M., Apan, M., \& Oztel, A. (2015). An evaluation of the financial performance of REITs in Borsa Istanbul: A case study using the entropy-based TOPSIS method. International Journal of Financial Research, 6(2), 124-138.

[7] Jha, G. K., Chatterjee, P., Chatterjee, R., \& Chakraborty, S. (2013). Suppliers selection in manufacturing environment using Range of Value Method. i-Manager's Journal on Mechanical Engineering, 3(3), 15.

[8] Li, L., Liu, F., \& Li, C. (2014). Customer satisfaction evaluation method for customized product development using Entropy weight and Analytic Hierarchy Process. Computers \& Industrial Engineering, 77, 80-87. 
[9] Li, X., Wang, K., Liu, L., Xin, J., Yang, H., \& Gao, C. (2011). Application of the entropy weight and TOPSIS method in safety evaluation of coal mines. Procedia Engineering, 26, 2085-2091.

[10] Liu, H. C., You, J. X., You, X. Y., \& Shan, M. M. (2015). A novel approach for failure mode and effects analysis using combination weighting and fuzzy VIKOR method. Applied Soft Computing, 28, 579-588.

[11] Madić, M., Radovanović, M., \& Manić, M. (2016). Application of the ROV method for the selection of cutting fluids. Decision Science Letters, 5(2), 245-254.

[12] Madić, M., Radovanović, M., Coteata, M., Janković, P., \& Petković, D. (2015). Multi-Objective optimization of Laser Cutting Using ROV-Based Taguchi Methodology. In Applied Mechanics and Materials, 809, 405-410. Trans Tech Publications.

[13] Madić, M. \& Radovanović, M. (2015). Ranking of some most commonly used nontraditional machining processes using Rov And Critic Methods, U.P.B. Sci. Bull., Series D, 77 (2), 193-204.

[14] Mon, D. L., Cheng, C. H., \& Lin, J. C. (1994). Evaluating weapon system using fuzzy analytic hierarchy process based on entropy weight. Fuzzy sets and systems, 62(2), 127-134.

[15] Pani, M. R., Verma, R., \& Sahoo, G. (2012). A heuristic method for supplier selection using AHP, entropy and TOPSIS. International Journal of Procurement Management, 5(6), 784-796.

[16] Root W. H. (1996), Apples and Apples Processing", in Processing Fruits: Science and Technology, Edited by Somogyi LP, Barrett DM and Hui YH, Volume 2, CRC Press, Florida.

[17] Safari, H., Fagheyi, M. S., Ahangari, S. S., \& Fathi, M. R. (2012). Applying Promethee method based on entropy weight for supplier selection. Business management and strategy, 3(1), 97-106.

[18] Salazar, R. Yakowitz, D. \& Duckstein, L. (1998). Comparison of several multi-objective techniques to optimize water management in an irrigation district in Quanajuato, Mexico, Multiple Objective Decision Support Systems for Land, Water, and Environment, 1225.

[19] Shannon C. E. (1948). A mathematical theory of communications. Bell Systems Technical Journal, 27(3), 379-423.

[20] Shemshadi, A., Shirazi, H., Toreihi, M., \& Tarokh, M. J. (2011). A fuzzy VIKOR method for supplier selection based on entropy measure for objective weighting. Expert Systems with Applications, 38(10), 12160-12167.

[21] Wu, J., Sun, J., Liang, L., \& Zha, Y. (2011). Determination of weights for ultimate cross efficiency using Shannon entropy. Expert Systems with Applications, 38(5), 5162-5165.

[22] Xu, J., Feng, P., \& Yang, P. (2016). Research of development strategy on China's rural drinking water supply based on SWOT-TOPSIS method combined with AHP-Entropy: A case in Hebei Province. Environmental Earth Sciences, 75(1), 58.

[23] Yakowitz, D. S., Lane, L. J., \& Szidarovszky, F. (1993). Multi-attribute decision making: dominance with respect to an importance order of the attributes. Applied Mathematics and Computation, 54(2-3), 167-181.

[24] Yakowitz, D.S. \& Hipel, K.W. (1997). Multiple objective decision making for Lokahi (balance) in environmental management. Applied Mathematics and Computation, 83, 97-115.

[25] Yakowitz, D.S., Lane, L., 1997. Targeting farms to improve water quality. Applied Mathematics and Computation 83, 173-194.

[26] Zhang, H., Gu, C. L., Gu, L. W., \& Zhang, Y. (2011). The evaluation of tourism destination competitiveness by TOPSIS \& information entropy-A case in the Yangtze River Delta of China. Tourism Management, 32(2), 443-451.

[27] Zhengyuan, J., Chunmei, W., Zhiwei, H., \& Gang, Z. (2011). Evaluation research of regional power grid companies' operation capacity based on entropy weight fuzzy comprehensive model. Procedia Engineering, 15, 4626-4630.

[28] Zou, Z. H., Yi, Y., \& Sun, J. N. (2006). Entropy method for determination of weight of evaluating indicators in fuzzy synthetic evaluation for water quality assessment. Journal of Environmental Sciences, 18(5), 1020-1023. 